\begin{tabular}{ll|l} 
Case Reports in & \multicolumn{2}{c}{ Case Rep Gastroenterol 2014;8:264-269 } \\
\cline { 2 - 3 } Gastroenterology & $\begin{array}{l}\text { DOI: 10.1159/000368075 } \\
\text { Publisned onine: September 10, 2014 }\end{array}$ & $\begin{array}{l}\text { ○ 2014 S. Karger AG, Basel } \\
\text { www.karger.com/crg }\end{array}$ \\
\hline & $\begin{array}{l}\text { This is an Open Access article licensed under the terms of the Creative Commons } \\
\text { Attribution-NonCommercial 3.0 Unported license (CC BY-NC) (www.karger.com/OA- } \\
\text { license), applicable to the online version of the article only. Distribution permitted for non- } \\
\text { commercial purposes only. }\end{array}$
\end{tabular}

\title{
Spinal Cord Ischemia Secondary to Transcatheter Arterial Chemoembolization for Hepatocellular Carcinoma
}

\author{
Aziz Bazine $^{\mathrm{a}} \quad$ Mohamed Fetohi $^{\mathrm{a}} \quad$ Maha Ait Berri $^{\mathrm{b}} \quad$ Ismail Essaadi $^{\mathrm{c}}$ \\ Kamal Elbakraouid ${ }^{d}{\text { Mohamed } \text { Ichou }^{c} \text { Hassan Errihani }}^{d}$ \\ ${ }^{a}$ Department of Medical Oncology, Military Hospital My Ismail, Meknès; Departments of \\ ${ }^{b}$ Neurology and ${ }^{\mathrm{C}}$ Medical Oncology, Military Hospital Med V, and ${ }^{\mathrm{d}}$ Department of Medical \\ Oncology, National Institute of Oncology, Rabat, Morocco
}

\section{Key Words}

Hepatocellular carcinoma $\cdot$ Transcatheter arterial chemoembolization $\cdot$ Spinal cord ischemia . Paraplegia

\begin{abstract}
Transcatheter arterial chemoembolization (TACE) is accepted worldwide as an effective treatment for patients with unresectable hepatocellular carcinoma. Although considered relatively safe, TACE has been associated with several complications. Spinal cord ischemia secondary to TACE is an extremely rare but disastrous complication. We report a very rare case of spinal cord injuries after TACE, together with a literature review. During the procedure, the patient suddenly experienced sensory impairment below the T10 dermatome and bilateral lower extremity motor weakness. She was given high-dose steroids and supportive therapy. The sensory deficits nearly improved completely, but motor strength remained unchanged. Thereafter, a chest computed tomography scan showed tumor metastasis to the lungs. The patient is now receiving sorafenib and follow-up.

(C) 2014 S. Karger AG, Basel
\end{abstract}

\section{Introduction}

Hepatocellular carcinoma (HCC) is a major health problem worldwide as more than 700,000 cases are diagnosed yearly. It is one of the leading causes of cancer-related death and is currently the main event leading to death in patients with cirrhosis [1]. Many patients 
Bazine et al.: Spinal Cord Ischemia Secondary to Transcatheter Arterial Chemoembolization for Hepatocellular Carcinoma

with HCC present advanced-stage disease when first diagnosed. There is a variety of different therapeutic modalities used to treat advanced HCC [2]. Transcatheter arterial chemoembolization (TACE) is one of the main methods for unresectable HCC [3]. Although considered a relatively safe procedure, TACE may be associated with multiple side effects. Neurological deficits after TACE are very rare and usually due to lipoidal embolism in the central nervous system. Spinal cord injury is an extremely rare complication after TACE and can lead to significant morbidity [4]. Here, we report a rare case of paraplegia that occurred after TACE to treat HCC, and review the previous literature.

\section{Case Report}

A 62-year-old woman with a history of insulin-dependent diabetes was diagnosed with advanced HCC. She was admitted to our institution for her first course of TACE via the proper hepatic artery by using a mixture of $30 \mathrm{ml}$ Lipiodol, $50 \mathrm{mg}$ cisplatin and $50 \mathrm{mg}$ doxorubicin, as well as gelatin sponge particles $(1,400-2,000 \mu \mathrm{m})$ and coils $(5 \times 8 \mathrm{~mm})$. On admission, she had Child-Pugh class $A$ hepatitis $C$ virus-associated cirrhosis and did not complain of any neurological symptoms or signs. Upon physical examination, blood pressure was 132/87 $\mathrm{mm} \mathrm{Hg}$, and pulse rate, respiratory rate and body temperature were normal. The results of a blood test were as follows: hemoglobin $11.8 \mathrm{~g} / \mathrm{dl}$ (normal 12.0-18.0), white blood cell count $6,450 / \mathrm{mm}^{3}$ (normal 4,000-10,000), platelet count 190,000/mm $\mathrm{mm}^{3}$ (normal 150,000-450,000) and albumin $39 \mathrm{~g} / \mathrm{l}$ (normal 38-50). Coagulation time, liver function studies and renal function were within normal range.

During TACE, the patient suddenly experienced sensory impairment below the T10 dermatome and bilateral lower extremity motor weakness. This was associated with urinary retention. Neurological examination revealed weakness of the lower extremities (Medical Research Council grade 2+ on the right side and 1+ on the left side). Somatic senses were prominently impaired below dermatome T10 without loss of proprioception. Deep tendon reflex of both legs was accelerated with positive sign of Babinski reflex. Spinal magnetic resonance imaging (MRI) was performed $24 \mathrm{~h}$ after the TACE procedure and revealed increased intramedullary signal intensity at the T10 level in T2-weighted images (fig. 1, fig. 2).

The patient was given high-dose steroids $(1 \mathrm{~g}$ of methyl prednisolone per day for 5 days) and supportive therapy while urinary retention was treated by placement of a urinary catheter into the bladder. Functional exercise was added during the following days. The sensory deficits nearly improved completely, but motor strength remained unchanged. Thereafter, a chest computed tomography scan showed tumor metastasis to the lungs. The patient is now receiving $400 \mathrm{mg}$ oral sorafenib bi-daily on a continuous basis and follow-up.

\section{Discussion}

HCC is a common cause of cancer-related deaths throughout the world [5]. The dominant arterial vascular supply of HCC provides the rationale to treat these cancers with TACE $[1,6]$. A cumulative meta-analysis of informative trials has positioned TACE as the first-line option for Barcelona Clinic Liver Cancer B patients (multifocal HCC without vascular invasion and/or extrahepatic spread, Child-Pugh class A-B, performance status 0 ), with a median survival exceeding 4 years [1].

Although the positive characteristics of TACE are its being less invasive and relatively safe, TACE may be associated with multiple side effects [7]. A common adverse event is post- 
Bazine et al.: Spinal Cord Ischemia Secondary to Transcatheter Arterial Chemoembolization for Hepatocellular Carcinoma

TACE syndrome, which is characterized by fever, abdominal pain, nausea and vomiting, leukocytosis and elevated liver enzymes lasting for a few hours to a few days. Other important complications of TACE are decompensation of cirrhosis, hepatic failure and renal failure which, although uncommon, are among the major treatment-related complications that may result in significant morbidity. Other important adverse events, including infection of the necrotic tumor presenting as liver abscess and tumor lysis syndrome, can also occur $[5,7,8]$. Unintentional extrahepatic embolizations are one of the serious side effects in TACE, and have been reported in only $4.6 \%$ of patients. They lead to splenic infarction, acute cholecystitis and necrosis, pancreatitis, gastric erosions, or ulcers, pulmonary infarction, stenosis of the biliary tract and neurological complications [2, 9].

Among the infrequent ischemic complications, neurological complications occur rarely in association with TACE and are usually caused by cerebral embolism. Spinal cord ischemia secondary to TACE is extremely rare, with a prevalence rate of $0.3 \%$ but disastrous consequences $[2,9,10]$.

Spinal cord injury after TACE usually occurs after the second or third session, which can be explained by hepatic artery injury or decreased flow at the previous TACE site, leading to collateral recruitment [4]. Sometimes it may result from the inadvertent embolization of spinal branches arising from intercostal or lumbar collateral vessels $[9,11]$. The clinical symptoms and signs of spinal cord injuries usually manifest about $6-8 \mathrm{~h}$ after the procedure as paresthesias, impaired sensory function, parapareses or paraplegias and urinary retention [4, 9]. MRI findings are usually normal in the acute phase, but hyperintensities on T2weighted images and focal cord enlargement are expected after 1-2 days, followed even later by cord enhancement after gadolinium administration. The sensitivity and specificity of MRI can be increased by repeated MRI in patients suspected of acute spinal cord ischemia [12].

There are no clear treatment guidelines. General medical care will depend on the severity of spinal cord ischemia. Patients with high thoracic or cervical infarction should be admitted to intensive care for close monitoring of vital signs and neurological status. In addition to rehabilitative measures, meticulous care must be given to bowel and bladder function as well as to the skin [13]. Patients with minor symptoms and signs initially tended to recover slowly, with a peak at 3-4 weeks, after which additional improvement was not apparent, but patients with more severe symptoms and signs initially might not recover $[4,9]$.

In conclusion, we have reported a very rare case of spinal cord injuries after TACE, together with a literature review. This case report emphasizes the fact that TACE can be associated with disastrous side effects which may lead to significant morbidity. To prevent these serious complications, an individualized therapy plan, including evaluation for a shunt and choice of the vessels used for the Lipiodol infusion prior to TACE, is of great importance to achieve a good overall result.

\section{Disclosure Statement}

The authors have no conflicts of interest to declare. 
Bazine et al.: Spinal Cord Ischemia Secondary to Transcatheter Arterial Chemoembolization for Hepatocellular Carcinoma

\section{References}

1 Bruix J, Gores J, Mazzaferro V: Hepatocellular carcinoma: clinical frontiers and perspectives. Gut 2014;63:844-855.

2 Chang SC, Ki HK, Geom SS, et al: Cerebral and pulmonary embolisms after transcatheter arterial chemoembolization for hepatocellular carcinoma. World J Gastroenterol 2008;14:4834-4837.

-3 Xie F, Xu F, Yang J, Wu M: Analysis of serious complications of transcatheter arterial chemoembolization for the treatment of hepatocellular carcinoma. J Med Coll PLA 2007;22:62-64.

4 Tufail K, Araya V, Azhar A, et al: Paraparesis caused by transarterial chemoembolization: a case report. World J Hepatol 2010;2:289-291.

-5 Tasneem AA, Abbas Z, Luck NH, et al: Adverse events following transarterial chemoembolization for hepatocellular carcinoma and factors predicting such events. J Pak Med Assoc 2013;63:239-244.

6 Nophadol V: Transarterial chemoembolization for hepatocellular carcinoma. Thammasat Med J 2014;14: 216-231.

7 Xia J, Ren Z, Ye S, et al: Study of severe and rare complications of transarterial chemoembolization (TACE) for liver cancer. Eur J Radiol 2006;59:407-412.

8 Wu L, Yang YF, Liang J, et al: Cerebral lipiodol embolism following transcatheter arterial chemoembolization for hepatocellular carcinoma. World J Gastroenterol 2010;16:398-402.

9 Kim JH, Yeon JE, Jong YK, et al: Spinal cord injury subsequent to transcatheter arterial chemoembolization in patients with hepatocellular carcinoma. Dig Liver Dis 2010;42:67-70.

$\checkmark 10$ Park SJ, Kim CH, Kim JD, et al: Spinal cord injury after conducting transcatheter arterial chemoembolization for costal metastasis of hepatocellular carcinoma. Clin Mol Hepatol 2012;18:316-320.

11 Kim HC, Chung JW, Lee W, et al: Recognizing extrahepatic collateral vessels that supply hepatocellular carcinoma to avoid complications of transcatheter arterial chemoembolization. Radiographics 2005;25 (suppl 1):S25-S39.

12 Alblas CL, Bouvy WH, Lycklama À, Nijeholt GJ, Boiten J: Acute spinal-cord ischemia: evolution of MRI findings. J Clin Neurol 2012;8:218-223.

13 Balami JS, Chen RL, Buchan AM: Stroke syndromes and clinical management. Q J Med 2013;106:607-615. 
Bazine et al.: Spinal Cord Ischemia Secondary to Transcatheter Arterial Chemoembolization for Hepatocellular Carcinoma

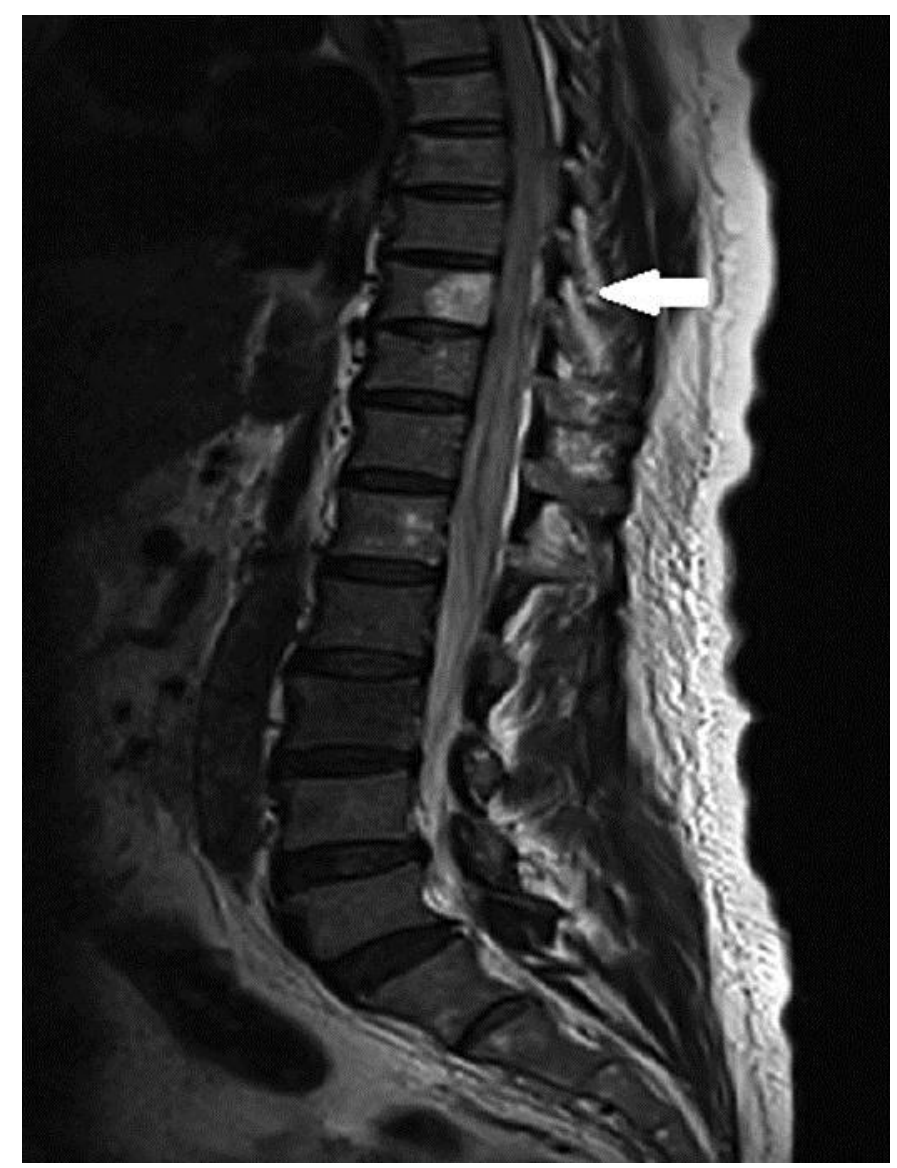

Fig. 1. T2-weighted sagittal MRI of the spine showing increased intramedullary signal intensity at the T10 level. 
Bazine et al.: Spinal Cord Ischemia Secondary to Transcatheter Arterial

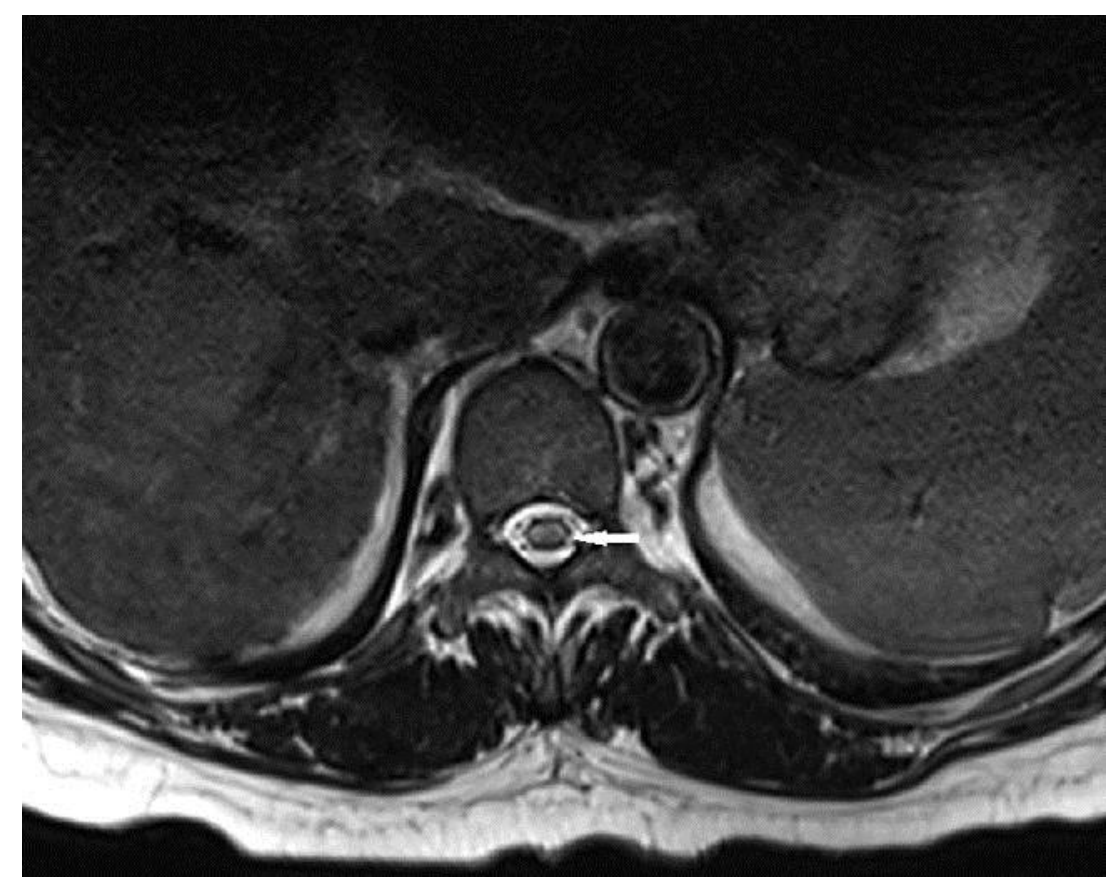

Fig. 2. T2-weighted axial MRI of the thoracic spine at the T10 level showing increased signal intensity of the spinal cord. 